\title{
Novel Measurement Method to Study Thermal Aspects of Molding Mixture Decomposition
}

\author{
József Tamás Svidróa*, Attila Diószegia \\ a Jönköping University School of Engineering, Department of Materials and Manufacturing, Gjuterigatan 5 \\ Box 1026, SE-55111 Jönköping, Sweden \\ *e-mail: jozsef.svidro@ju.se
}

Received: 7 September 2018/Accepted: 15 October 2018/Published online: 31 October 2018 This article is published with open access by AGH University of Science and Technology Press

\begin{abstract}
A wide variety of molding mixtures are extensively used in the process of the sand casting of metal components today. The sector is continuously developing in production volume; moreover, the expectations of customers are increasing on a monthly basis (also from a quality point of view). Even though mold and core manufacturing are well-organized routines in most foundries, technological problems still appear that can lead to technological problems and casting defects. These trends are forcing metal casters to come up with fitting strategies to solve their daily production challenges, while their suppliers are expected to keep up the continuous development of their existing foundry products and to find innovative solutions as well as new material combinations. Research on molding materials and their properties must, therefore, take a step forward accordingly to generate the necessary new knowledge to understand the behavior of mold and core mixtures during casting.

This paper summarizes the latest results of a novel measurement method suitable for studying the degradation characteristics of different molding materials from a new perspective. The fundamentals of the method are based on a thermal analysis, focusing on the heat-absorption behavior of greensand and two types of chemically bonded sands regardless of the binder type and amount or the manufacturing process.
\end{abstract}

\section{Key words:}

cold-box, epoxy resin, greensand, molding mixture, thermal analysis

\section{INTRODUCTION}

Thermal analysis in the form of recording and interpreting temperature variations of a cooled or heated material over time is widely used today in foundry technology [1]. The broad areas of application mainly cover works based on cooling curve analyses of both non-ferrous and ferrous alloys [2-4]. Recently, studies applying traditional methods such as TG-DSC-DTG have been conducted to examine materials that are applicable as bonding agents in foundry purpose mold and core-making technologies [5]. Other sand-related works deal with the measurement of thermophysical properties in greensand molds while applying real foundry conditions $[6,7]$.

The proposed measurement method is based on Fourier thermal analysis (FTA) and is used in an inverse way to interpret the heat distribution versus time curves recorded in sand samples. The aim was to obtain a new understanding of the thermal aspects of the degradation processes in various molding mixtures. Thus, the heat absorption behavior by mixture decomposition was measured and calculated.

\section{EXPERIMENTAL SETUP AND MATERIALS}

The foundation of the experimental setup is the application of spherical sand samples of 40,50 , and $60 \mathrm{~mm}$ diameters.
Two N-type thermocouples with stainless steel sheaths were placed in the specimens with the aim to record the temperature; one in the geometrical center, and another at a lateral measuring point near the sample wall (Fig. 1).

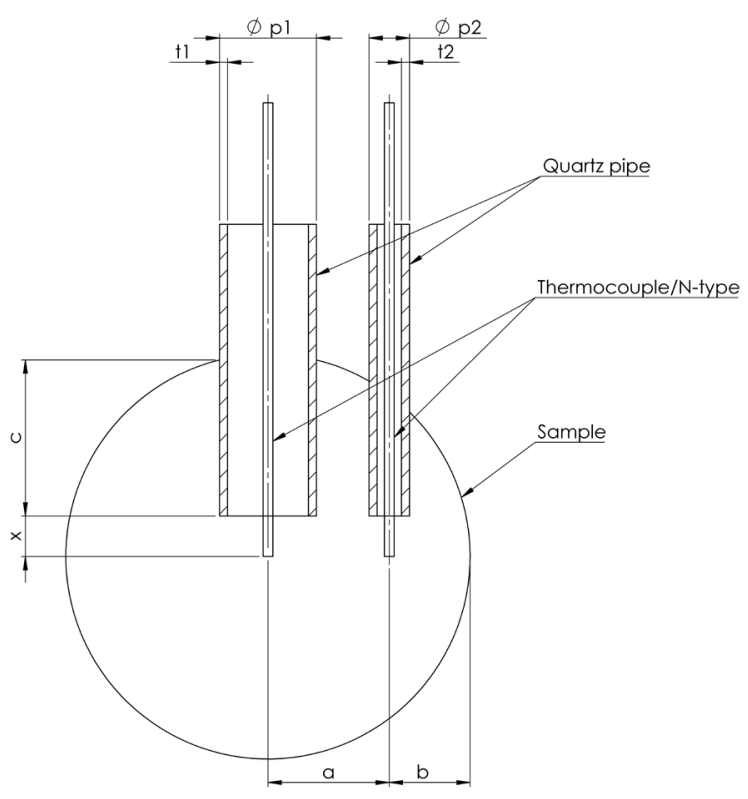

Fig. 1. Sample geometry [8-10] 
Protective pipes of quartz glass with a wall thickness of $1 \mathrm{~mm}(t 1$ and $t 2$ in Figure 1 ) were used to protect the thermocouples as the specimens are immersed into liquid metal during the measurement. The diameters of the protective pipes (øp1 and $\varnothing p 2$ in Figure 1) were chosen according to previous works [8-10]. The size variations of the specimens and their direct contact with the liquid metal (as a heat source) during the tests ensured real foundry conditions. The exact locations of the temperature-reading points concerning all three diameters were according to Table 1.

Table 1

Positions of measuring points

\begin{tabular}{|c|c|c|c|c|}
\hline \multirow{2}{*}{$\begin{array}{c}\text { Diameter of } \\
\text { specimen, } \\
\text { mm }\end{array}$} & \multicolumn{4}{|c|}{$\begin{array}{c}\text { Dimensions, } \\
\text { mm }\end{array}$} \\
\hline & $a$ & $\boldsymbol{b}$ & $c$ & $x$ \\
\hline 40 & 10 & 10 & 15 & 5 \\
\hline 50 & 15 & 10 & 20 & 5 \\
\hline 60 & 20 & 10 & 25 & 5 \\
\hline
\end{tabular}

The molding mixtures investigated in this work were greensand, epoxy-SO $\mathrm{S}_{2}$, and polyurethane cold-box (PUCB) chemically bonded systems. They were all prepared with the same type of washed and screened silica sand with a light brown color, sub-rounded shape, and a medium grain size of $0.23 \mathrm{~mm}$. The composition variables were set according to the typical industrial application of each mixture (Tab. 2). The specimens were not coated before the measurements. The epoxy- $\mathrm{SO}_{2}$ and PUCB mixtures were tested without drying; however, the greensand samples were dried for 2 hours at $105^{\circ} \mathrm{C}$ to increase their integrity for the thermocouple placement procedure. The samples were then immersed into liquid iron at $1300 \pm 10^{\circ} \mathrm{C}$, and the temperature distribution in both measuring points was recorded.

Table 2

Production parameters of studied mixtures

\begin{tabular}{lc}
\hline Mixture & Composition, wt.\%* \\
\hline Greensand & $8 \%$ bentonite, 3.3\% water, 3\% coal dust \\
\hline Epoxy-SO ${ }_{2}$ & $\begin{array}{c}1 \% \text { epoxy resin }+30 \% * * \text { hydroperoxide } \\
\text { (cured by } \mathrm{SO}_{2} \text { gas) }\end{array}$ \\
\hline PUCB & $\begin{array}{c}0.9 \% \text { phenolic resin }+0.9 \% \text { isocyanate } \\
\text { (cured by amine vapor) }\end{array}$ \\
\hline $\begin{array}{l}\text { * by mass of sand } \\
* * \text { by mass of resin }\end{array}$ & \\
\hline
\end{tabular}

\section{RESULTS AND DISCUSSION}

In this paper, the results of the 50-mm-diameter samples were primarily considered for further investigations. Figure 2 shows the temperature distribution over time in the 50 -mm-diameter samples of all three mixtures. The temperature recordings at the lateral points near the sample walls showed faster heating (Fig. 2b) when compared to the curves at the central measuring point (Fig. 2a). The differences in the heating rates were due to the various distances of the temperature-recording positions from the heat source.

a)

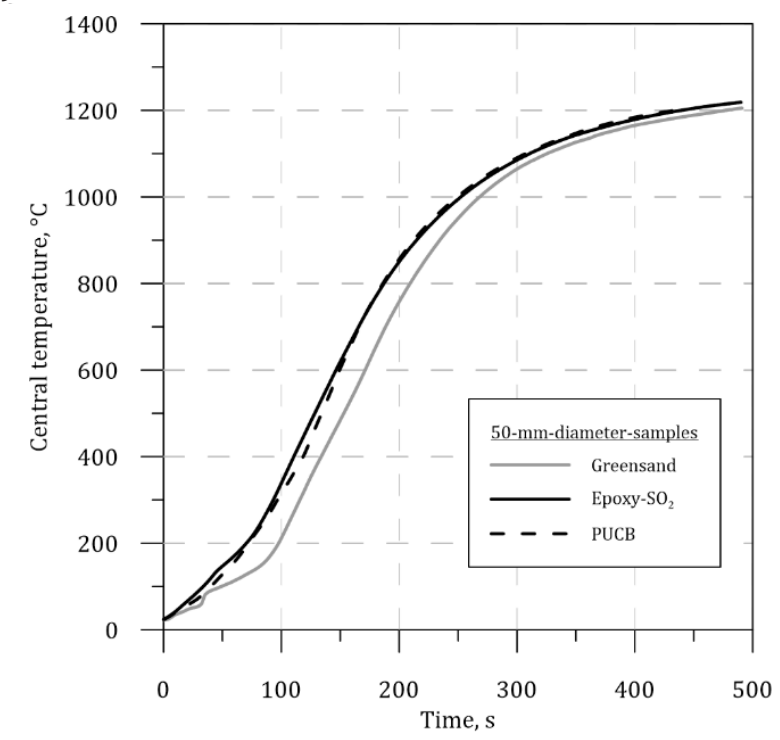

b)

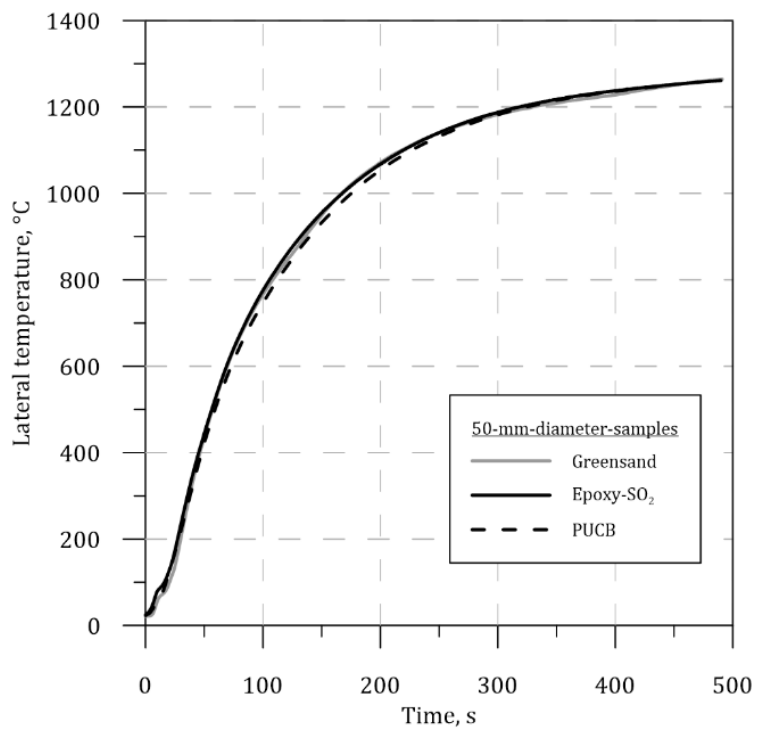

Fig. 2. Temperature distribution versus time in centers of 50-mm-diameter samples (a) and near sample walls (b) for all studied mixtures

On the other hand, differences due to the various binder types in the mixtures did not clearly appear. The reason for this is that the temperature of the liquid iron ensured a generally high heating rate and the relatively fast procession of the expected heat absorbing and binder degradation processes. Therefore, with the aim to learn more about the differences between the three mixtures, the heating curves were further processed by Fourier thermal analysis. Based on the initial measurements of the temperature distribution inside the samples, a Fourier 
thermal analysis was run, and the total absorbed heat values $(L)$ were calculated for the 50 -mm-diameter specimens of each mixture (shown in the legends of Figures 3-5). These values correspond to the amount of heat taken away from the melt by different processes; the decomposition of the bound and crystalline water in the lattice structure of the bentonite, the swelling and volatilization of the coal dust in the greensand, and the degradation of the organic resins and their catalysts and reactants in the chemically bonded mixtures. The results showed that greensand absorbed a significantly higher amount of heat as compared to the lower values of the epoxy- $\mathrm{SO}_{2}$ and PUCB mixtures. The heat absorption behavior was further investigated by determining its temperature dependency by plotting the rate of heat absorption versus the temperature inside the geometrical centers of the samples (Figs. 3-5).

The heat absorption and degradation profile of the greensand and its features are shown in Figure 3. Heat absorption started intensively in the beginning, peaking at around $150^{\circ} \mathrm{C}$ in the sand; therefore, the vaporization process of the bound water took a significant amount of heat from the melt. At higher sand temperatures, the swelling and volatilization of the coal dust in the green sand produced additional maximum heat absorption peaks from between 300 and $550^{\circ} \mathrm{C}$; however, this process overlapped the loss of crystalline water in the lattice structure of the bentonite. According to Figure 3, the heat absorption processes were finished in the greensand by up to $700^{\circ} \mathrm{C}$.

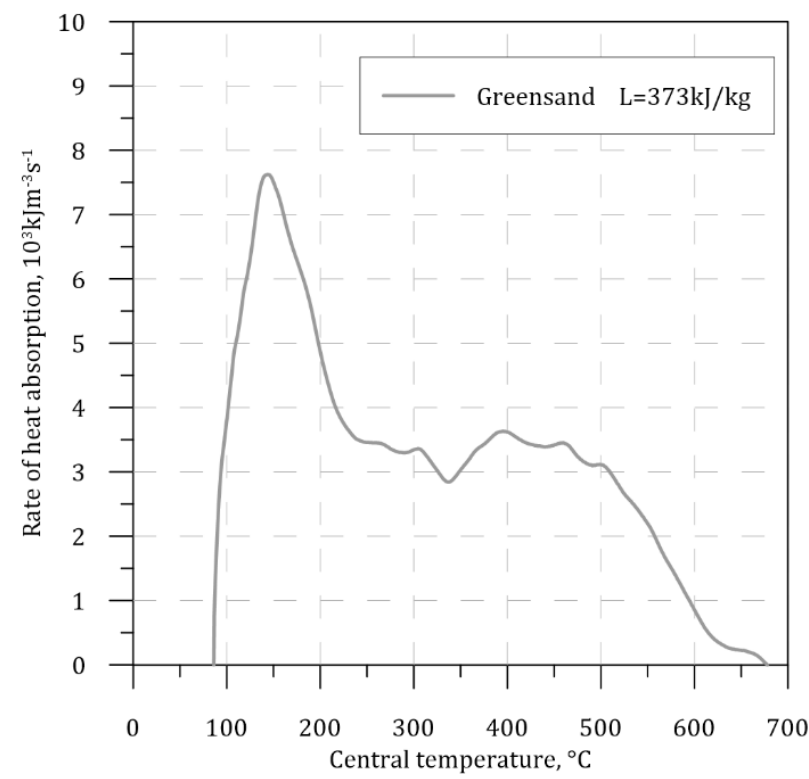

Fig. 3. Heat absorption and degradation profile of greensand versus temperature in center of 50-mm-diameter sample

Figure 4 shows the heat absorption and degradation profile of the epoxy- $\mathrm{SO}_{2}$ mixture. The heat absorption reached an initial maximum at lower sand temperatures $\left(150^{\circ} \mathrm{C}\right)$ due to the vaporization of the free moisture and bound water in the system (but at a significantly lower rate when compared to the greensand result). The endothermic process of the epoxy resin degradation started as the temperature rose in the sample and continued until $500^{\circ} \mathrm{C}$. This process was assumed to overlap the combustion of the degradation products. Besides the initial peak, the epoxy- $\mathrm{SO}_{2}$ mixture showed a relatively smooth heat absorption and degradation profile.

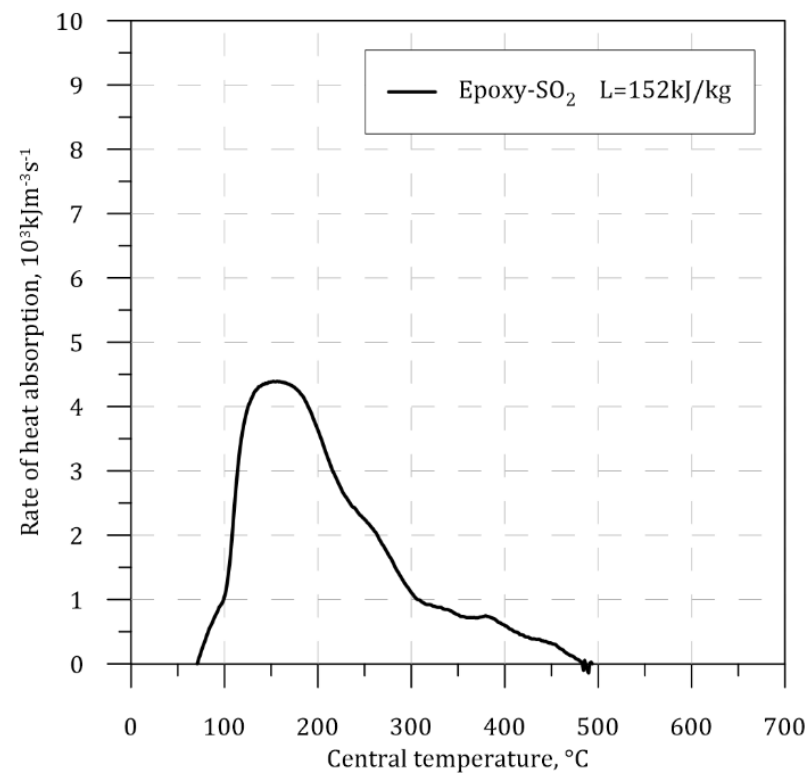

Fig. 4. Heat absorption and degradation profile of epoxy- $\mathrm{SO}_{2}$ mixture versus temperature in center of 50 -mm-diameter sample

The heat absorption and degradation characteristic of the PUCB mixture are shown in Figure 5. The rate of heat absorption reached the initial maximum shortly above $100^{\circ} \mathrm{C}$ (similar to the epoxy- $\mathrm{SO}_{2}$ system) when the decomposition of the free moisture and bound water in the mixture components occurred. However, the degradation of the polyurethane showed multiple major stages at $250^{\circ} \mathrm{C}$ and $350-450^{\circ} \mathrm{C}$ as notable maximums of heat absorption appeared on the curves. The PUCB mixture, therefore, displayed a more complex multi-staged decomposition process.

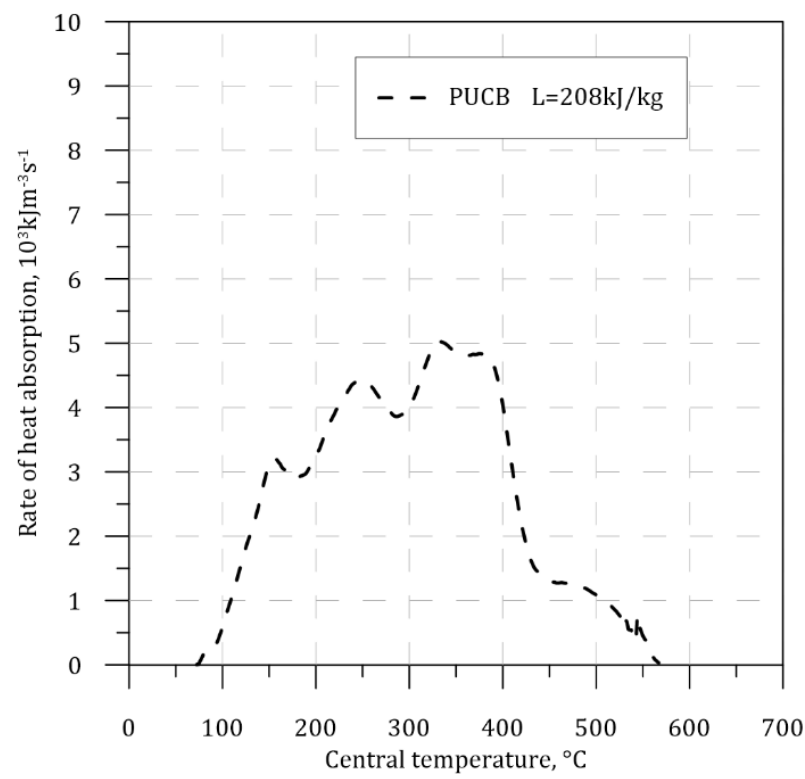

Fig. 5. Heat absorption and degradation profile of PUCB mixture versus temperature in center of 50 -mm-diameter sample 


\section{CONCLUSION}

In this work, conventional molding mixtures were studied by a new method based on Fourier thermal analysis. The results showed that greensand absorbed considerably more heat from the liquid metal than chemically bonded systems such as epoxy- $\mathrm{SO}_{2}$ and PUCB mixtures. All three mixtures showed diverse degradation profiles. The heat absorption behavior can be directly interpreted as the cooling ability of the mixtures.

Greensand exhibited a major maximum peak of heat absorption and cooling ability at lower sand temperatures, together with additional maximums due to the swelling and volatilization of the coal dust at higher sand temperatures. The studied chemically bonded mixtures also showed initial maximums but at a moderate rate when compared to the greensand as well as similar multiple peaks at the later stages of the degradation by the PUCB mixture. The epoxy- $\mathrm{SO}_{2}$ mixture showed a relatively smooth heat absorption and degradation profile.

The maximums of the heat absorption at specific sand temperatures is expected to eventuate in the improved cooling ability of the cores, which is expected to shorten the solidification time in the casting (affecting its final microstructural morphology) and may result in large variations in the mechanical properties. Future work is, therefore, planned to further study and prove the relationship between the heat absorption capacity of sand mixtures and the mechanical properties of castings.

\section{Acknowledgements}

The present work was financed by the Swedish Knowledge Foundation. Cooperating parties in the project are Jönköping University, Scania CV AB, and Volvo Powertrain Production Gjuteriet $A B$.

\section{REFERENCES}

[1] Stefanescu D.M. (2015). Thermal Analysis - Theory and applications in metal casting. International Journal of Metalcasting, 9(1), 7-22. Doi:10.1007/BF03355598.

[2] Krupiński M., Krupińska B., Rdzawski Z., Labisz K. \& Tański T. (2015). Additives and thermal treatment influence on nonferrous alloys. Journal of Thermal Analysis and Calorimetry, 120(3), 1573-1583. Doi:10.1007/s10973-015-4497-0.

[3] Bartosová M., Pribulová A., Eperjesi S. \& Futás P. (2018). Analyisis of cooling curves of nodular cast iron. Journal of Casting and Materials Engineering, 2(1), 1-4. Doi:10.7494/ jcme.2018.2.1.1.

[4] Diószegi A., Diaconu V.L. \& Fourlakidis V. (2016). Prediction of volume fraction of primary austenite at solidification of lamellar graphite cast iron using thermal analyses. Journal of Thermal Analysis and Calorimetry, 124(1), 215-225. Doi:10.1007/s10973-018-7088-z.

[5] Grabowska B., Malinowski P., Szucki M. \& Byczyński L. (2016). Thermal analysis in foundry technology. Journal of Thermal Analysis and Calorimetry, 126(1), 245-250. Doi:10.1007/s10973-016-5435-5.

[6] Krajewski P.K. \& Piwowarski G. (2015). Range of thermal conductivity changes of wet green foundry sand during casting solidification. Archives of Metallurgy and Materials, 60(3B), 2391-2395.

[7] Krajewski P.K., Piwowarski G., Żak P.L. \& Krajewski W.K. (2014). Experiment and numerical modelling the time of plate-shape casting solidification vs. thermal conductivity of mould material. Archives of Metallurgy and Materials, 59(4), 1405-1408. Doi:10.1515/amm-2015-0390.

[8] Lidumnieks K., Svidró J.T. \& Diószegi A. (2017). The effect of various production parameters on the heat absorbing capacity of greensand. International Journal of Cast Metals Research, 31(1), 7-13. Doi:10.1080/13640461.2017.1348005.

[9] Svidró J.T., Diószegi A., Svidró J. \& Ferenczi T. (2017). Thermophysical aspects of reclaimed sand addition to the epoxy- $\mathrm{SO}_{2}$ coremaking system studied by Fourier thermal analysis. Journal of Thermal Analysis and Calorimetry, 130(3), 1779-1789. Doi:10.1007/s10973-017-6612-x.

[10] Svidró J.T., Diószegi A., Svidró J. \& Ferenczi T. (2017). The effect of different binder levels on the heat absorption capacity of moulding mixtures made by the phenolic urethane cold-box process. Journal of Thermal Analysis and Calorimetry, 130(3), 1769-1777. Doi:10.1007/s10973-017-6611-y. 